\title{
Ketosis (acetonaemia) in dairy cattle farms: practical guide based on importance, diagnosis, prevention and treatments
}

\begin{abstract}
Ketosis is an important metabolic disease in dairy cattle which is occurring due to increase of ketone bodies (especially $\beta$-hydroxybutyrate) in blood. It is a lactation disorder usually associated with intense milk production and negative energy balance in dairy cattle. Ketosis most times is occurring at the most productive stage of the lactation and makes great financial damages in milk production. In this practical review, incidence and prevalence, etiology, clinical aspects, biochemical findings, diagnosis methods and prevention methods and treatments of ketosis in dairy cattle farms are briefly discussed. Prevalence rate of ketosis is closely related to diet and farm management and also it is identified to be closely related to animal's genetics. Concentration of serum $\beta$-hydroxybutyrate between $1,200-1,400 \mu \mathrm{mol} / \mathrm{L}$ is usually threshold for definition of ketosis and clinical (wasting and nervous) and sub-clinical ketosis are two differentially aspects of ketosis in dairy cattle, which are defined according to presence or absence of clinical signs of ketosis in cattle. Prevention of ketosis based on efficient diet, periodic blood, milk and/or urine screening for ketone bodies' detection, and also body score evaluation in dairy cattle farms are the best methods to early detection of ketosis in animals which can be easily applicable in dairy cattle farms.
\end{abstract}

Keywords: clinical ketosis, dairy cattle farm, practical guide, sub-clinical ketosis
Volume 7 Issue 6 - 2018

\author{
Samin Madreseh-Ghahfarokhi,' Azam \\ Dehghani-Samani, ${ }^{2}$ Amir Dehghani-Samani ${ }^{3}$ \\ 'Department of Clinical Sciences, Faculty of Veterinary Medicine, \\ Ferdowsi University of Mashhad, Mashhad, Iran \\ ${ }^{2}$ Faculty of Veterinary Medicine, Shahrekord University, \\ Shahrekord, Iran \\ ${ }^{3}$ Department of Clinical Sciences, Faculty of Veterinary Medicine, \\ Shahrekord University, Shahrekord, Iran
} Correspondence: Amir Dehghani Samani, Department of
Clinical Sciences, Faculty of Veterinary Medicine, Shahrekord
University, Shahrekord, I I5, Iran, Tel +98-38|4424427, Fax +98 38I4424427, Email amerds2008@gmail.com

Received: March 28, 2018| Published: December 18, 2018

\section{Introduction}

Transition period between late pregnancy and early lactation (also called the periparturient period) certainly is the most interesting stage of the lactation cycle. Classically length of transition period has been defined as the last 3 weeks before parturition to 3 weeks after parturition. ${ }^{1,2}$ Most important infectious diseases and metabolic disorders occur during this time. Ketosis, retained fetal membranes, milk fever, merits, and displaced abomasums primarily impact cows during the periparturient period. Susceptibility to infectious diseases in this period occurs due to immune suppression during the periparturient period..$^{1-3}$ Ketosis (acetonemia) is an increase of ketone bodies (acetone, acetoacetate, and $\beta$-hydroxybutyrate, subsequently referred to as ketones) in blood until they eventually begin to spill over into urine and/or milk. In dairy cows, ketosis is a lactation disorder usually associated with intense milk production and negative energy balance. ${ }^{4}$ Ketosis occurs at the most productive stage of the lactation and hence can be extremely costly, as reported by different researchers. $^{5-7}$

\section{Incidence and prevalence}

Prevalence rate of ketosis is closely related to diet and farm management and different amounts of prevalence rate have been reported, some researchers reported that it is between 11.1-12.1 percent, ${ }^{5,7}$ but defiant researchers reported that that in some herds in the United Kingdom, up to $33 \%$ of cows tested positive for milk or urine ketones, lost weight, and had decreased milk production. ${ }^{8}$ Emery et al., ${ }^{9}$ reported that about $50 \%$ of the cows in some high-producing herds had at least subclinical ketosis and that 20 to $30 \%$ of the subclinical cases developed into clinical ketosis. Death due to lactation ketosis is not common. ${ }^{4}$ It is identified that prevalence of ketosis is higher in exotic pure/crossbreds than native pure/non-descript. The prevalence is found to be significantly associated with breeds of cattle. There is a high prevalence of ketosis in animals of high genetic potential, as these animals are unable to withstand the pressures arising from the high nutritional demands generated by the production of milk, which ultimately results in development of hypoglycemia that can remain as a challenge to the successful dairy farming business, eventually ruining the life of dairy farmers. ${ }^{5}$ It is identified that ketosis and fatty liver syndrome in dairy cattle are closely related to each other ${ }^{10}$ and the average annual costs of ketosis and fatty liver syndrome in United States are estimated to be over $\$ 60$ million. ${ }^{11}$

\section{Definition and etiology}

Ketosis is a major metabolic disorder of dairy cows in early lactation, which develops when dairy cows fall into a condition of excessively negative energy balance caused by insufficient dietary intake and generous lactation, and characterized by relatively high concentrations of the ketone bodies acetoacetate, $\beta$-hydroxybutyrate (BHBA) and acetone, and a concurrent low concentration of glucose in the blood. A concentration of serum BHBA greater than 1,200-1,400 $\mu \mathrm{mol} / \mathrm{L}$ is a common standard used for the diagnosis of ketosis. ${ }^{12-16}$ During early lactation, the requirement for glucose is increased significantly because the production of lactose rises dramatically. Thus, fat mobilization is increased in adipose tissue and more nonesterified fatty acids (NEFAs) are absorbed in the mitochondria of liver cells. Elevated concentrations of NEFA increase lipogenesis and Ketogenesis in hepatocytes. High concentrations of ketone bodies 
decrease the rates of $\beta$-oxidation of fatty acids, gluconeogenesis and the citric acid cycle in hepatocytes. However, contradictory results on the metabolic changes in the liver during ketosis have been reported, with some studies indicating that gluconeogenesis is unchanged in ketogenic situations. ${ }^{12,17-20}$ The most widespread hypothesis indicates that acetyl-CoA is directed towards incomplete oxidation (Ketogenesis) as a result of low accessibility of oxaloacetate in the mitochondria. ${ }^{21}$ However, this theory has been criticized, as it is documented that the activity of phosphoenolpyruvate carboxykinase in the mitochondria and cytosol is unchanged in ketogenic situations, and that the gluconeogenic flux is diminished in fasted animals. ${ }^{20}$ Krebs' theory which indicates that maintaining a low level of oxaloacetate is the cause of Ketogenesis is probably correct, but the reasoning for it is wrong: the low concentration of oxaloacetate is achieved by a much higher $\mathrm{NADH} / \mathrm{NAD}^{+}$ratio in the mitochondria than in the cytoplasm. This should result in a minimal rate of intramitochondrial phosphoenolpyruvate formation under ketogenic conditions, accounting for the lower rate of gluconeogenesis during ketotic periods with inappetance. ${ }^{22}$ Many researchers have investigated the etiology of ketosis, often leading to contradictory opinions. ${ }^{20,23-25}$ Briefly, ketosis and/or fatty liver occur when physiologic mechanisms for the adaptation to negative energy balance fail. Failure of hepatic gluconeogenesis to supply adequate glucose for lactation and body needs may be one cause of ketosis; however, poor feedback control of nonesterified fatty acid release from adipose tissue is another likely cause of ketosis and fatty liver. The types of ketosis resulting from these two metabolic lesions may require different therapeutic and prophylactic approaches. ${ }^{26}$

\section{Clinical aspects and biochemical findings}

Clinical and sub-clinical ketosis are two differentially aspects of ketosis in dairy cattle, which are defined according to presence or absence of clinical signs of ketosis in cattle. As mentioned before, concentration of serum BHBA between 1,200-1,400 $\mu \mathrm{mol} / \mathrm{L}$ is threshold for definition of ketosis and if mentioned increase of BHBA concentration be occurred with clinical signs it will be named as clinical ketosis and Subclinical ketosis is defined as elevated concentrations of circulating ketone bodies in the absence of clinical signs. ${ }^{14}$ Two major clinical forms of bovine ketosis are described (wasting and nervous) but these are the two extremes of a range of syndromes in which wasting and nervous signs are present in varying degrees of prominence. ${ }^{27}$ The wasting form is most common of the two and is manifest with a gradual but moderate decrease in appetite and milk yield over 2-4 days. In herds that feed components separately the pattern of appetite loss is often unusual in that the cow first refuses to eat grain, then ensilage but may continue to eat hay. The appetite may also be depraved. ${ }^{27}$ In the nervous form, signs are usually bizarre and begin quite suddenly. The syndrome is suggestive of delirium rather than of frenzy and the characteristic signs include: walking in circles, straddling or crossing of the legs, head pushing or leaning into the stanchion, apparent blindness, aimless movements and wandering, vigorous licking of the skin and inanimate objects, depraved appetite, chewing movements with salivation. ${ }^{27}$ Hypoglycemia, ketonemia and ketonuria are characteristic of the disease. ${ }^{27}$ Blood glucose levels are reduced from the normal of approximately $50 \mathrm{mg} / \mathrm{dL}$ to $20-40 \mathrm{mg}$ / dL. Ketosis secondary to other diseases is usually accompanied by blood glucose levels above $40 \mathrm{mg} / \mathrm{dL}$ and often above normal. ${ }^{27} \mathrm{As}$ mentioned before increase of ketone bodies especially BHBA is the most important biochemical characteristic which occurs due to ketosis. $^{5-7}$

\section{Diagnosis}

Blood screening: periodic blood screening of herd for BHBA concentration is the easiest way to early detection of ketosis in cattle but plasma BHBA is not a cost effective or convenient analysis for routine analysis and cow side monitoring and the content of acetoacetate or BHBA in urine and milk are used for these purposes. Concentrations of BHBA and acetoacetate in urine and milk are less than those in blood and the correlation coefficients for blood and milk BHBA and blood and milk acetoacetate are 0.66 and 0.62 , respectively. ${ }^{27,28}$ Cowside tests have the advantage of being inexpensive, giving immediate results, and they can be used as frequently as necessary. A minor source of error is that the concentration of ketone bodies in these fluids will depend not only on the ketone level of the blood but also on the amount of urine excreted or on the milk yield. Milk is less variable, easier to collect and may give fewer false negatives with subclinical ketosis. $^{27}$ Milk and urine ketone levels have been traditionally detected by the reaction of acetone and acetoacetate with sodium nitroprusside and can be interpreted in a semi-quantitative manner based on the intensity of the reaction. Several products are available commercially as test powders or strips are commonly accompanied by a color chart that allows a classification in grades such as negative, trace, small, moderate, large, based on the intensity of the color of the reaction. ${ }^{27}$ Conventional wisdom is that milk powder tests are not sensitive for detection of subclinical ketosis (report too many false negatives) and urine tests are not sufficiently specific (report too many false positives). ${ }^{27,29}$ Milk and/or urine screening: the sensitivity and specificity of the nitroprusside powder test with milk in various studies is reported as $28-90 \%$ and $96-100 \%$, respectively. ${ }^{27-30}$ More recently, a milk strip test detecting the presence of BHBA in milk is available and is graded on the concentration of BHBA in $\mu \mathrm{lmol} / \mathrm{L}$. In different studies it has a reported sensitivity and specificity of 73$96 \%$ and $69-96 \%$, respectively. ${ }^{27-32}$ These variations are, in part, due to different plasma BHBA reference values $(1200$ and $1400 \mu \mathrm{mol} / \mathrm{L})$ for designation of subclinical ketosis and different cut points used in urine BHBA. Somatic cell counts greater than 1 million cells $/ \mathrm{mL}$ will cause an elevation in reading of both the BHBA strip test and the nitroprusside tests. ${ }^{27}$ A nitroprusside tablet has a reported sensitivity and specificity of $100 \%$ and $59 \%$, respectively, compared with serum BHBA concentrations above 1400 flmollL16 and a nitroprusside strip test a reported sensitivity and specificity of $78 \%$ and $96 \%$ with a urine cut point corresponding to 'small' on the color chart or $49 \%$ and $99 \%$ with a urine cut point corresponding to 'moderate' on the color chart. ${ }^{27,29} \mathrm{BHBA}$ test strips when used with urine has a reported sensitivity and specificity of $73 \%$ and $96 \%$, respectively at a urine cut point of $100 \mu \mathrm{mol} / \mathrm{L}$ BHBA and $27 \%$ and $99 \%$ at a urine cut point of $200 \mu \mathrm{mol} / \mathrm{L} \mathrm{BHBA}^{29}$

\section{Prevention and treatments}

Prevention of clinical ketosis is integrally related to the adequate nutrition of the cows, management of body condition, and the use of certain feed additives in the dry and lactating period. Dry matter intake, fiber digestibility, particle size distribution, energy density, fat incorporation in early lactation rations, protein content, feeding systems and rumen size are important subjects which have to be mentioned to preparation of perfect diets in dairy cattle. ${ }^{27}$ Daily use of sodium propionate $(0.25 \mathrm{lb}$. for each cow $)$ after calving is identified to be preventive against ketosis in dairy cattle farms. Treated cows with sodium propionate not only have higher blood sugar levels and lower blood ketone bodies in their blood, but also have higher 
milk production. ${ }^{33}$ Oral propylene glycol administration is found to be sharply preventive for ketosis in dairy cattle farms and also to be efficient for make obvious increase in milk production in dairy cattle. Researchers reported that treated cows with $300 \mathrm{ml}$ oral propylene glycol daily produced $0.23 \mathrm{~kg}$ more milk per milking in the first $30 \mathrm{~d}$ of lactation, for a total difference of $0.69 \mathrm{~kg} / \mathrm{cow}$ per day. Also propylene glycol -treated cows were 1.50 times more likely to resolve their subclinical ketosis and 0.54 times less likely to develop clinical ketosis. These results show the positive effects of oral propylene glycol administration in fresh cows with sub-clinical ketosis by helping to resolve their sub-clinical ketosis and preventing clinical ketosis. In addition, oral propylene glycol improves milk yield during early lactation in cows diagnosed with sub-clinical ketosis. ${ }^{34}$ It is identified that propylene glycol most likely reduces fatty acid mobilization from adipose tissue and by this mechanism can be protective against ketosis and fatty liver syndrome. ${ }^{35}$ Ruminally-protected choline has preventive effects against imbalanced energy levels in ketosis and/ or fatty liver syndrome. It is also identified that choline probably enhances hepatic very low-density lipoproteins secretion. ${ }^{35}$ Also shortening or eliminating the dry period is a management strategy that reduces the magnitude of negative energy balance after calving and triglyceride accumulation in the liver and can be protective against metabolic diseases related to imbalanced energy levels like ketosis. ${ }^{35} \mathrm{It}$ was also reported that prevalence and incidence of subclinical ketosis were significantly reduced $(50 \%)$ due to monensin-based treatment in dry cows and heifers. The duration of subclinical ketosis for cows that had been treated with monensin was also shorter than others. Monensin treatment significantly reduced the incidence of subclinical ketosis. In addition, monensin significantly reduced the prevalence of positive milk ketone bodies tests. ${ }^{36}$ Some of researchers reported that intravenous injection of $500 \mathrm{~mL}$ of a $50 \%$ solution of glucose results in transient hyperglycemia, increased insulin and decreased glucagon secretion, and reduced plasma concentration of non-esterifies fatty acids. It effects a marked improvement in most cows but relapses occur commonly unless repeated treatments are used. ${ }^{27}$ Other sugars, especially fructose, either alone or as a mixture of glucose and fructose (invert sugar), and xylitol, have been used in an effort to prolong the response but idiosyncrasies to some preparations, in the form of polypnea, muscle tremor, weakness and collapse, can occur while the injection is being given. ${ }^{27}$ To overcome the necessity for repeated injections, propylene glycol can be administered as a drench. The traditional does is $225 \mathrm{~g}$ twice daily for 2 days, followed by $110 \mathrm{~g}$ daily for 2 days to cattle, but higher volumes are also used. Propylene glycol (200-700g daily), or salts of propionic acid, can be administered in the feed and give good results. ${ }^{27}$ Efficiency of glucocorticoids in the treatment of bovine ketosis has been demonstrated in both experimental and field cases. Hyperglycemia occurs within $24 \mathrm{~h}$ of administration and appears to result from a repartitioning of glucose in the body rather than from gluconeogenesis..$^{27,37}$ Insulin facilitates cellular uptake of glucose, suppresses fatty acid metabolism and stimulates hepatic gluconeogenesis. It is administered in conjwlction with either glucose or a glucocorticoid and may be of particular value in early-onset cases of ketosis that are unresponsive to glucose or corticosteroid therapy but is not commonly used. The dose of protamine zinc insulin is 200-300IU per animal administered SC every $24-48 \mathrm{~h}$ as required. ${ }^{27}$ Anabolic steroids have also been used for treatment of lactational ketosis and ketoses in late pregnant cows that are over-fat, stressed, or has twin fetuses. Experimentally, $60 \mathrm{mg}$ and $120 \mathrm{mg}$ of trenbolone acetate are effective as single injections but no extensive field trials are recorded and the drug is banned for use in food animals in most countries. ${ }^{27}$ Glucagon although ketogenic is strongly gluconeogenic and glycogenolytic and glucagon concentrations are decreased in the blood of fat cows at calving and cows with ketonemia. It could be of value in prevention and therapy but it would require a prolonged delivery system as it has a very short physiologic half-life and its effects following a single injection are short-lived. ${ }^{27,38}$

\section{Conclusion}

Ketosis (clinical form and/or sub-clinical form) is an important disease in dairy cattle farms which results in great mentionable financial damages to milk production due to its effects on health and/ or production of dairy cattle. In this practical review, incidence and prevalence, etiology, clinical aspects, biochemical findings, diagnosis methods and prevention methods and treatments of ketosis in dairy cattle farms are briefly discussed. Prevention of ketosis based on efficient diet, periodic blood and/or milk or urine screening for ketone bodies detection and body score evaluation in dairy cattle farms are the best methods to early detection of ketosis in animals which can be easily applicable in dairy cattle farms.

\section{Acknowledgments}

None

\section{Conflicts of interest}

Authors certify there are no financial and personal relationships with other people or organizations which could influence or bias their work and declare there is no conflict of interest.

\section{References}

1. Drackley JK. Biology of dairy cows during the transition period: The final frontier? J Dairy Sci. 1999;82(11):2259-2273.

2. Grummer RR. Impact of changes in organic nutrient metabolism on feeding the transition dairy cow. J Anim Sci. 1995;73(9):2820-2833.

3. Mallard BA, Dekkers JC, Ireland MJ, et al. Alteration in immune responsiveness during the peripartum period and its ramification on dairy cow and calf health. J Dairy Sci. 1998;81(2):585-595.

4. Littledike ET, Young JW, Beitz DC. Common Metabolic Diseases of Cattle: Ketosis, Milk Fever, Grass Tetany, and Downer Cow Complex. $J$ Dairy Sci. 1981;64(6):1465-1482.

5. Thirunavukkarasu M, Kathiravan G, Kalaikannan A, et al. Prevalence of ketosis in dairy farms-A survey in Tamil Nadu. Tamilnadu J Vet Anim Sci. 2010;6(4):193-195.

6. Reist M, Koller A, Busato A, et al. First ovulation and ketone body status in the early postpartum period of dairy cows. Theriogenology. 2000;54(5):685-701.

7. Østergaard S, Gröhn YT. Concentrate feeding, dry-matter intake, and metabolic disorders in Danish dairy cows. Livest produ Sci. 2000;65(1):107-118.

8. Hibbitt KG. Bovine ketosis and its prevention. Vet Rec. 1979;105(1):13.

9. Emery RS, Burg N, Brown LD, et al. Detection, Occurrence, and Prophylactic Treatment of Borderline Ketosis with Propylene Glycol Feeding. J Dairy Sci. 1964;47(10):1074-1079.

10. Veenhuizen JJ, Drackley JK, Richard MJ, et al. Metabolic Changes in Blood and Liver During Development and Early Treatment of Experimental Fatty Liver and Ketosis in Cows. J Dairy Sci. 1991;74(12): 4238-4253. 
11. Bobe G, Young JW, Beitz DC. Invited review: pathology, etiology, prevention, and treatment of fatty liver in dairy cows. J Dairy Sci. 2004;87(10):3105-3124.

12. Xu C, Wang Z, Liu GW, et al. Metabolic characteristic of the liver of dairy cows during ketosis based on comparative proteomics. Asian-Aust J Anim Sci. 2008;21(7):1003-1010.

13. Ingvartsen KL. Feeding-and management-related diseases in the transition cow: Physiological adaptations around calving and strategies to reduce feeding-related diseases. Anim Feed Sci Technol. 2006;126(3-4):175-213.

14. Melendez P, Goff JP, Risco CA, et al. Incidence of subclinical ketosis in cows supplemented with a monensin controlled-release capsule in Holstein cattle, Florida, USA. Prev Vet Med. 2006;73(1):33-42.

15. Geishauser T, Leslie K, Tenhag J, et al. Evaluation of eight cow-side ketone tests in milk for detection of subclinical ketosis in dairy cows. $J$ Dairy Sci. 2000;83(2):296-299.

16. Oetzel GR. Monitoring and testing dairy herds for metabolic disease. Vet Clin: Food Anim Pract. 2004;20(3):651-674.

17. Danfær A, Tetens V, Agergaard N. Review and an experimental study on the physiological and quantitative aspects of gluconeogenesis in lactating ruminants. Comp Biochem Physiol B Biochem Mol Biol. 1995;111(2):201-210

18. Cadórniga-Valiño C, Grummer RR, Armentano LE, et al. Effects of fatty acids and hormones on fatty acid metabolism and gluconeogenesis in bovine hepatocytes. J Dairy Sci. 1997;80(4):646-656.

19. Rukkwamsuk T, Wensing T, Geelen MJ. Effect of fatty liver on hepatic gluconeogenesis in periparturient dairy cows. J Dairy Sci. 1999;82(3):500-505.

20. Kronfeld DS. Excessive gluconeogenesis and oxaloacetate depletion in bovine ketosis. Nutr Rev. 1969;27(5):131-133.

21. Krebs HA. Bovine ketosis. Vet Rec. 1966;78:187-192.

22. Zammit VA. Ketogenesis in the liver of ruminants-adaptations to challenge. J Agric Sci. 1990;115(2):155-162.

23. Grummer RR. Impact of changes in organic nutrient metabolism on feeding the transition dairy cow. J Anim Sci. 1995;73(9):2820-2833.

24. Drackley JK, Overton TR, Douglas GN. Adaptations of glucose and longchain fatty acid metabolism in liver of dairy cows during the periparturient period. J Dairy Sci. 2001;84:100-112.

25. Herdt TH. Ruminant adaptation to negative energy balance: Influences on the etiology of ketosis and fatty liver. Vet Clin: Food Anim Pract. 2000;16(2):215-230.

26. Herdt TH. Ruminant adaptation to negative energy balance: Influences on the etiology of ketosis and fatty liver. Vet Clin: Food Anim Pract. 2000;16(2):215-230.

27. Radostits OM, Gay CC, Hinchcliff $\mathrm{KW}$, et al. Veterinary Medicine: $A$ textbook of the diseases of cattle, horses, sheep, pigs and goats. Elsevier Health Sciences, Philadelphia. 2006.

28. Enjalbert F, Nicot MC, Bayourthe C, et al. Ketone bodies in milk and blood of dairy cows: Relationship between concentrations and utilization for detection of subclinical ketosis. J Dairy Sci. 2001;84(3):583-589.

29. Carrier J, Stewart S, Godden S, et al. Evaluation and use of three cowside tests for detection of subclinical ketosis in early postpartum cows. J Dairy Sci. 2004;87(11):3725-3735.

30. Geishauser T, Leslie K, Kelton D, et al. Evaluation of five cowside tests for use with milk to detect subclinical ketosis in dairy cows. J Dairy Sci. 1998;81(2):438-443

31. Geishauser T, Leslie K, Tenhag J, et al. Evaluation of eight cow-side ketone tests in milk for detection of subclinical ketosis in dairy cows. J Dairy Sci. 2000;83(2):296-299.

32. Dirksen G, Breitner W. A New Quick $\square$ Test for Semiquantitative Determination of Beta $\square$ Hydroxybutyric Acid in Bovine Milk. J Vet Med A. 1993;40(1 $\square 10): 779-784$.

33. Schultz LH. Use of Sodium Propionate in the Prevention of Ketosis in Dairy Cattle. J Dairy Sci. 1958;41(1):160-168

34. McArt JA, Nydam DV, Ospina PA, et al. A field trial on the effect of propylene glycol on milk yield and resolution of ketosis in fresh cows diagnosed with subclinical ketosis. J Dairy Sci. 2011;94(12):6011-6020.

35. Grummer RR. Nutritional and management strategies for the prevention of fatty liver in dairy cattle. Vet J. 2008;176(1):10-20.

36. Duffield TF, Sandals D, Leslie KE, et al. Efficacy of monensin for the prevention of subclinical ketosis in lactating dairy cows. J Dairy Sci. 1998;81(11):2866-2873.

37. Mills SE, Beitz DC, Young JW. Evidence for Impaired Metabolism in Liver during Induced Lactation Ketosis of Dairy Cows. J Dairy Sci. 1986;69(2):362-370.

38. Hippen AR. Glucagon as a potential therapy for ketosis and fatty liver. Veterinary Clinics of North America: Food Anim Pract. 2000;16(2):267-282. 